\title{
EXPERIMENTAL STUDY OF MELON CROP SEED DRYER PRODUCTIVITY
}

\author{
Alexander Dobrickiy, Dmitriy Bakharev, Alexander Pastukhov, Sergey Volvak \\ Belgorod State Agricultural University named after V. Gorin, Russia \\ sasha_yana@mail.ru,baharevdn_82@mail.ru,pastukhov_ag@mail.ru, volvak.s@yandex.ru
}

\begin{abstract}
Modern continuous drying equipment does not allow in one pass of the drying chamber to obtain seed grain of conditioned moisture from freshly released seeds of melon crops. To solve this problem, a high moisture melon crop seed dryer was designed, in which the principle of differential heat supply to forced mixed material was implemented. The design of the drying chamber provides for the supply of a heat carrier to the zone of predried seeds, which withstand a higher temperature, and then at a lower temperature to the zone with high moisture seeds that prevents them from cracking. Design and technological parameters and operating modes of the experimental dryer were experimentally investigated. Studies were carried out by means of a series of one-factor experiments in three stages: determining the productivity of the device for supplying seeds to the drying chamber, studying the transport ability of dryer elastic agitators, choosing a rational angle of inclination of the gas distribution sieve of the unloading device. The following parameters and consistent patterns are established: angle of inclination of gas distribution sieve of unloading device $14^{\mathrm{o}}$; seed supply to drying chamber 24-18 $\mathrm{kg} \cdot \mathrm{h}^{-1}$; revolutions per minute of elastic agitators, when the seeds are supplied to the drying chamber $24 \mathrm{~kg} \cdot \mathrm{h}^{-1}-4 \mathrm{~min}^{-1}$; when the seeds are supplied $22 \mathrm{~kg} \cdot \mathrm{h}^{-1}-4.75 \mathrm{~min}^{-1}$; at $20 \mathrm{~kg} \cdot \mathrm{h}^{-1}-6 \mathrm{~min}^{-1}$ and at $18 \mathrm{~kg} \cdot \mathrm{h}^{-1}$ $7 \mathrm{~min}^{-1}$; drying agent speed $5 \mathrm{~m} \cdot \mathrm{s}^{-1}$; specific energy intensity of pumpkin seed drying process was $1.27 \mathrm{kWh} \cdot \mathrm{kg}^{-1}$ with the dryer productivity $18 \mathrm{~kg} \cdot \mathrm{h}^{-1}$. The given research results make it possible to determine the rational rotation interval of the transporting working element, within which elastic agitators provide the required productivity and high quality of seed drying to conditioned moisture in one pass of the drying chamber against the direction of the drying agent movement.
\end{abstract}

Keywords: seeds, melon crops, dryer, elastic agitators, operating modes.

\section{Introduction}

Melon crop fruits are a dietary food for people of any age and are consumed both fresh and processed. Melons are a valuable source of a number of vitamins and trace elements, so they are widely used in the pharmaceutical and perfume industries [1-2]. Providing agricultural producers with a sufficient number of seeds with high grade and sowing qualities is an urgent task. Among the postharvesting operations of melons, drying seeds is the most difficult and responsible, since it determines the quality and shelf life of the sown material. The main features of the drying process of high moisture melon crop seed (HMMCS) include [2-6]:

- high starting moisture, which makes it difficult for the heat transfer agent to flow through the seed layer;

- during drying, the layer of seeds is coated with crust and deteriorates heat and mass exchange;

- pre-dehydration of seeds is required before drying,

- overheating of seeds leads to unacceptable shell cracking.

Modern continuous drying equipment does not allow in one pass of the drying chamber to obtain seed grain of conditioned moisture from freshly released seeds of melon crops. To solve this problem, a dryer HMMCS was designed, in which the principle of differential heat supply to forced mixed material was implemented. [7]. The design of the drying chamber provides for the supply of the heat transfer agent to the zone of pre-dried seeds that withstand a higher temperature, and then at a lower temperature to the zone with high moisture seeds that prevents them from cracking. A general view of the experimental dryer is shown in Fig. 1.

The operational efficiency of the proposed HMMCS dryer during convective drying is affected to varying degrees by a large number of factors that can be divided into the following groups:

- seed characteristics: hygroscopic, physical-mechanical, aerodynamic properties of seeds, quality of seed washing;

- characteristics of the drying agent: speed, temperature, enthalpy, moisture content;

- characteristics of the design features of the drying chamber and the dryer as a whole: supply of seeds into the drying chamber, angle of inclination of the gas distribution sieve of the unloading unit, speed of rotation of the elastic agitators the drying chamber, number of dryer sections, perforation diameter of the gas distribution sieve, dimensions of the drying chamber, etc. 


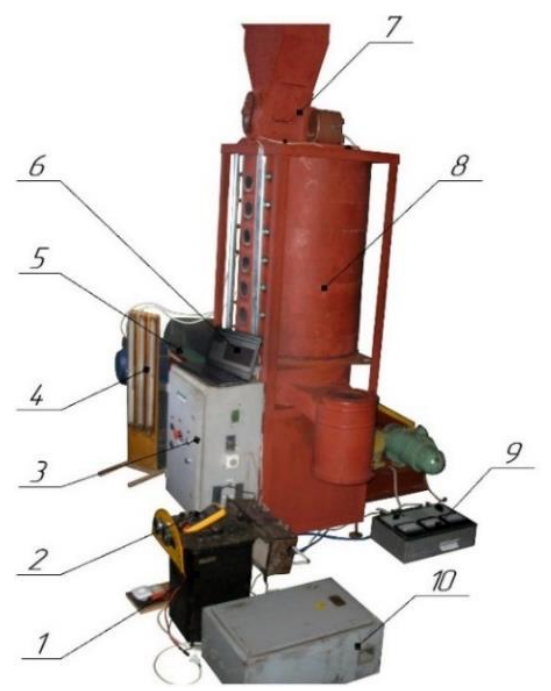

Fig. 1. General view of the experimental dryer: 1 - autotransformer LATR PHO-250-10; 2 - device DT9207A; 3 - dryer remote controller; 4 - U-shaped pressure gauge; 5 - unit for monitoring and setting of specified drying agent temperature; 6 - personal computer; 7 - wet seed feed mechanism; 8 - melon seed dryer; 9 - measuring set K-505; 10 - unit of energy indicator removal

The suggested Dryer HMMCS in which the principle of differential heat supply to forced mixed material was implemented is an innovative device, laboratory experimental studies of which were conducted in order to establish the regularities of the influence of the seed supply to the drying chamber, the angle of inclination of the gas distribution sieve of the unloading unit, the speed of rotation of the elastic agitators inside the drying chamber, the temperature conditions of drying on the efficiency of the dryer and the energy intensity of the process.

The experimental device (Fig. 2) is a complex system that consists of the following subsystems: hopper with a mechanism for feeding wet seeds to the drying chamber, divided by height into sections, drying chamber with a gas distribution sieve, heat generator, mechanism for driving the elastic agitators and gas distribution sieves inside the sections of the drying chamber, unloading unit and storage of the seed material.

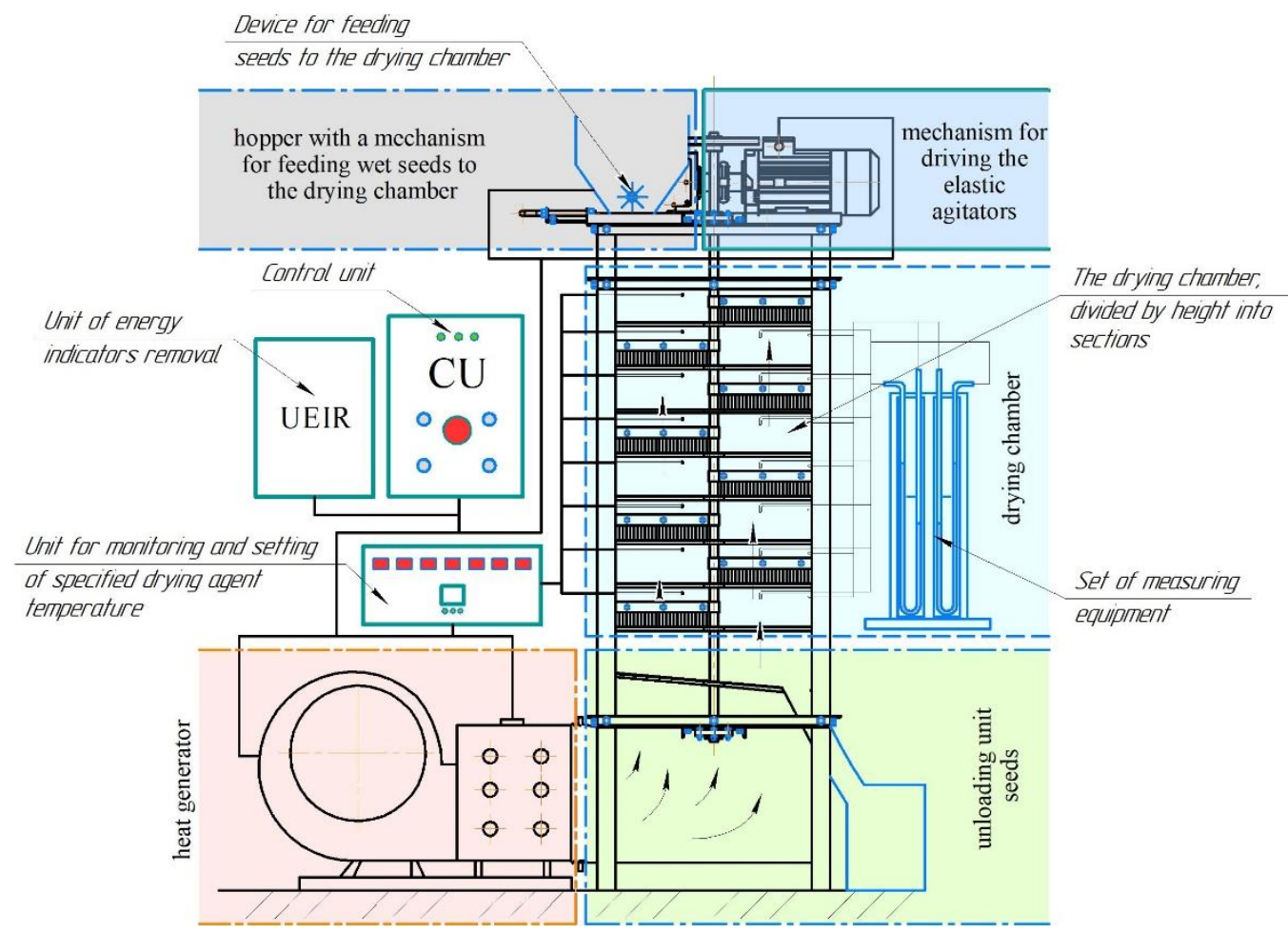

Fig. 2. Functional diagram of the experimental dryer device 


\section{Materials and methods}

The experiments considered the mechanical-technological and aerodynamic properties of pumpkin seeds of the "Volzhskaya Seraya" variety, deseeded from the fruits according to the well-known method [8]. After deseeding, the seeds were washed by hand in running water, then their humidity was brought to $33 \%$. The studies were conducted in the autumn period at an average air temperature of $15{ }^{\circ} \mathrm{C}$ and a relative humidity of $\varphi=75 \%$.

Analysis of existing scientific information and one-factor experimental studies have shown that the temperature of the drying agent should be in the range of 38 to $50^{\circ} \mathrm{C}[3-6 ; 8]$, and the speed of the drying agent in the lower section of the drying chamber should be $5 \mathrm{~m} \cdot \mathrm{s}^{-1}$, which does not exceed seed soaring rates of seeds, when opening the unloading and loading window of the lower section of the drying chamber.

Experimental studies were carried out through single factor experiments in three stages.

Step 1. Determining the productivity of the device for supplying seeds to the drying chamber. The device for supplying seeds to the drying chamber is a four-bladed drum dispenser that feeds wet seeds to the first section of the dryer. The productivity of the dispenser was determined by the well-known formula (1) [8].

$$
Q_{\sigma}=60 \cdot F_{\varkappa} \cdot n \cdot z \cdot l \cdot \gamma \cdot \varphi ; \mathrm{kg} \cdot \mathrm{h}^{-1},
$$

where $F_{\text {ж }}$ - cross-sectional area of a single gutter, $\mathrm{m}^{2}$;

$n$-drum rotation speed, $\mathrm{min}^{-1}$;

$l$ - length of the working part of the gutter, $\mathrm{m}$;

$z$ - number of gutter;

$\gamma$ - bulk weight of the material, $\mathrm{kg} \cdot \mathrm{m}^{-3}$;

$\varphi$ - fill factor $(\varphi=0.8-0.9)$.

When studying the productivity of the seed feeding device in the drying chamber, four total volumes of the working troughs of the paddle dispenser were installed alternately: $1.4 \cdot 10^{-3} \mathrm{~m}^{3}, 1.2 \cdot 10^{-3} \mathrm{~m}^{3}$, $1 \cdot 10^{-3} \mathrm{~m}^{3}$ and $0.8 \cdot 10^{-3} \mathrm{~m}^{3}$. Pumpkin seeds were loaded into the storage hopper of the loading unit, then, including the drive of the dispenser, the seeds were fed into the storage container for one minute. After the end of the experiment, the weight of the seed material was determined by weighing. The speed of rotation the seed feeder drive was $1 \mathrm{~min}^{-1}$. The experiments were carried out in five-fold repetition for $33 \%$ and $10 \%$ of the seed moisture content.

Step 2. Choosing a rational angle of inclination of the gas distribution sieve of the unloading unit. Unloading of seed material in the proposed HMMCS dryer is carried out by means of an air flow created by a fan along an inclined gas distribution sieve, and this requires an experimental determination of the rational angle of inclination of the sieve, at which continuous unloading of seed material will occur. For this purpose, an experimental device was developed that simulates the real process of unloading seeds from an inclined gas distribution sieve. The device consists of a frame, air ducts, an inclined gas distribution sieve (drying chamber), fixed on one side pivotally, and on the other side to the mechanism for changing the angle of inclination, a seed loading unit, and a centrifugal fan.

The following experiment was carried out on this device. The moisture-conditioned seeds $(9.5 \%)$ were filled into the loading hopper, where the seeds were fed by a dispenser to an inclined gas distribution sieve equipped with a mechanism for changing the angle of its inclination. The seeds were discharged from the drying chamber via an inclined sieve into a storage container under the influence of the air flow, and then were weighed on a scale. If the weight of the seeds in the storage container corresponded to the weight of the seeds when loaded into the drying chamber, then the angle of inclination of the sieve was considered rational. The air flow velocity was $5 \mathrm{~m} \cdot \mathrm{s}^{-1}$. The seed supply to the drying chamber was $24 \mathrm{~kg} \cdot \mathrm{h}^{-1}$, which corresponded to the maximum productivity of the paddle dispenser at $33 \%$ seed moisture. The volume of the gutters of the four-bladed dispenser was $1.4 \cdot 10^{-3} \mathrm{~m}^{3}$. The duration of the experience was 60 seconds. The angle of inclination of the gas distribution sieve varied within 6-18 .

Step 3. Studying the transport ability of elastic agitators of a dryer. The productivity of the dryer of the proposed design depends on the speed of rotation of the elastic agitators inside the sections of the drying chamber. Elastic agitators provide mixing and movement of seed material in the sections of the 
dryer. In this regard, it is important to know the rational speed of rotation of the agitators, at which the seeds continuously moving will receive the required conditioned moisture of $10 \%$.

When conducting studies of the transport ability of the elastic agitators for each capacity of the seed feeding device in the drying chamber $24,22,20$ и $18 \mathrm{~kg} \cdot \mathrm{h}^{-1}$ alternately, the rotation speed of the agitators was set in the range from 2.5 to $10 \mathrm{~min}^{-1}$. At the same time, the initial moisture content of the seeds was $33 \%$, the angle of inclination of the gas distribution sieve of the unloading unit was $14^{\circ}$, the speed of the drying agent was $5 \mathrm{~m} \cdot \mathrm{s}^{-1}$. The duration of the experiment was chosen based on the search experiments and was $60 \mathrm{~min}$. A three-fold repetition of the experiment was adopted that provided a relative error of the average value of less than $5 \%$.

\section{Results and discussion}

The data obtained as a result of the experimental studies were processed by methods of mathematical statistics and presented graphically. The results of determining the productivity of the device for feeding seeds to the drying chamber at a certain humidity are presented in the form of graphical dependencies (Fig. 3, a) and calculated by the formula (1). The analysis of the graphical dependence showed that with an increase in the working volume of the gutters of the four-bladed dispenser, the productivity of the device for feeding seeds to the drying chamber increases. In addition, at a fixed value of one volume of the gutters of the paddle dispenser, with a decrease in seed moisture, the productivity of the feed device increases, and with an increase in seed moisture, the productivity of the dispenser decreases. This is due to the influence of seed adhesion.

a)

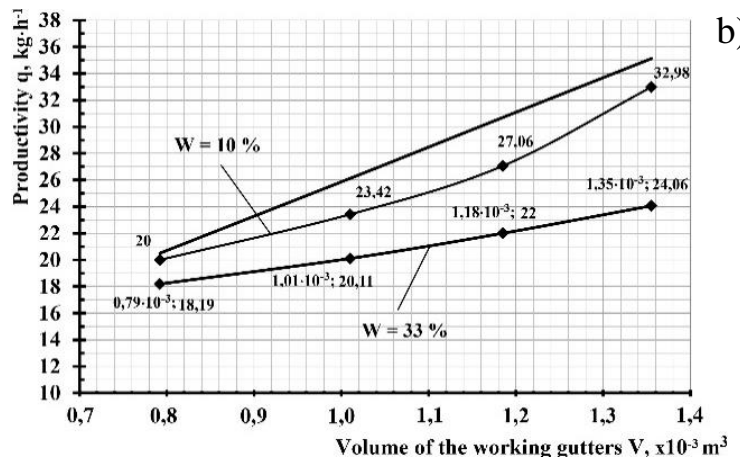

b)

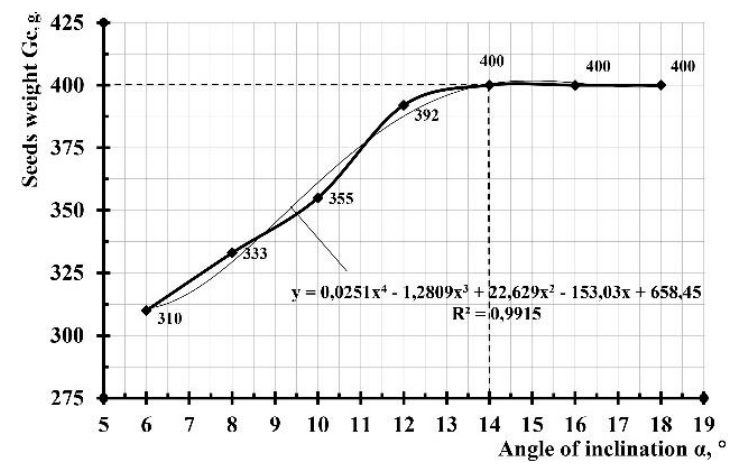

Fig. 3. Results of experimental studies: a - dependence of the productivity of the device for feeding seeds to the drying chamber on the volume of the working gutters of the dispenser at different seed moisture; $b$ - dependence of the descent of seed material from the inclined gas distribution sieve of the drying chamber on the angle of its inclination to the horizon;

$\longrightarrow$ - theoretical curve; $\longrightarrow-$ experimental curve

The results obtained in the experimental studies on finding the rational angle of inclination of the gas distribution sieve of the unloading unit are represented by a graphical dependence (Fig. 3, b). From the graph in Fig. 3, b at an angle of inclination of the gas distribution sieve of $14^{\circ}$, the best unloading of seed material from the inclined gas distribution sieve is achieved. This value of the angle of inclination is accepted in further studies as rational.

The results of the study of the transport ability of the dryer elastic agitators with different seeds feed are presented graphically in Fig. 4. From figure 4, a, curve $q_{\kappa c}$ it can be seen that, when seeds are fed into the drying chamber $24 \mathrm{~kg} \cdot \mathrm{h}^{-1}$ and the rotation speed is less than $4 \mathrm{~min}^{-1}$, the transport capacity of the elastic agitators decreases, which is explained by excessive overflow of the drying chamber. When the seeds are fed into the drying chamber 22, 20 and $18 \mathrm{~kg} \cdot \mathrm{h}^{-1}$ (Fig. 4, b, c, d) this effect is not observed. Based on this, we assume that the rational throughput of the drying chamber is provided at a speed of rotation of the agitators more than $4 \mathrm{~min}^{-1}$. To determine the specific values of the rotation speed of the elastic agitators with different seed feed into the drying chamber, a similar experiment was conducted, but with the use of the drying agent temperature of $50{ }^{\circ} \mathrm{C}$. In this experiment, moisture was measured at the exit of the seeds from the drying chamber. Based on the results of this experiment, the moisture curves $W$ are plotted in Fig. 4. From the $W$ curves in the graph (Fig. 4) it can be seen that with an increase in the speed of rotation of the elastic agitators more than $4 \mathrm{~min}^{-1}$, the required $10 \%$ conditioned moisture of the seeds at their exit from the drying chamber is not provided. 
a)

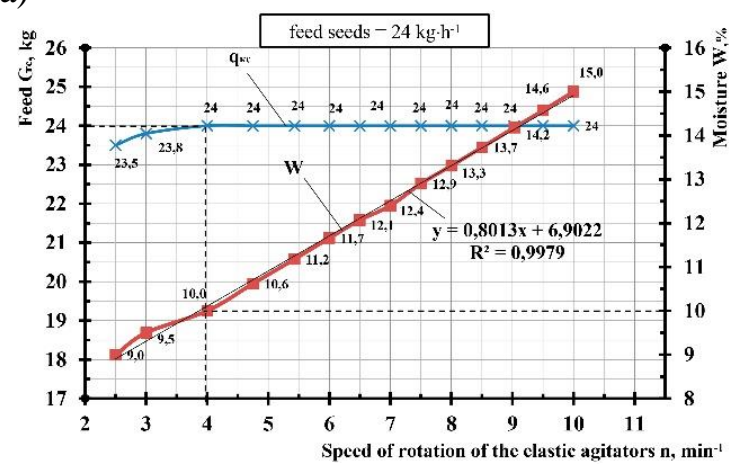

c)

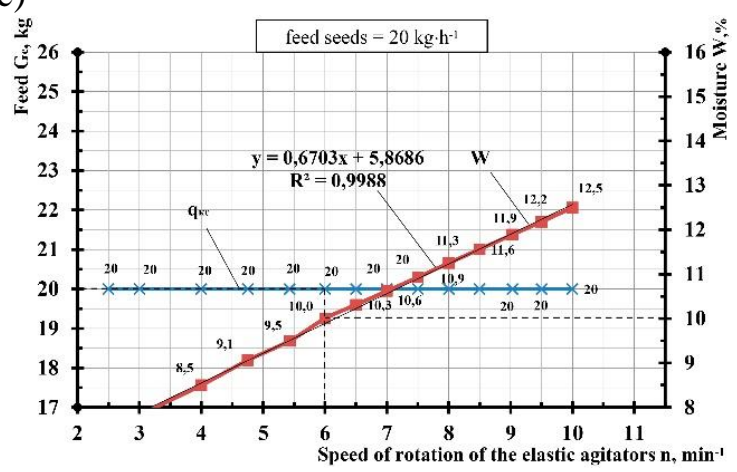

b)

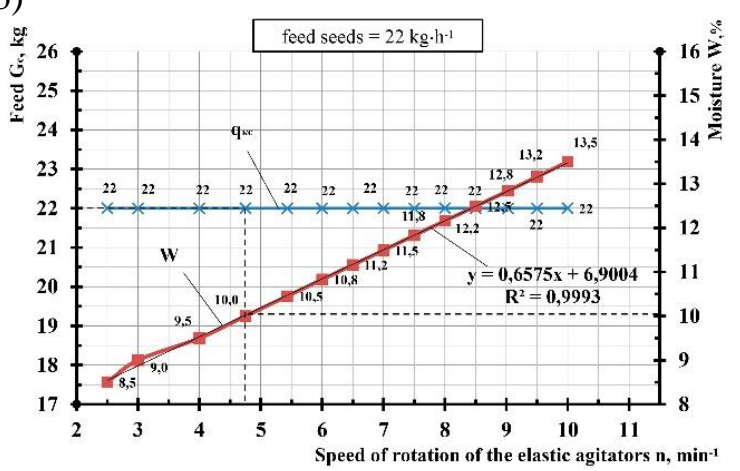

d)

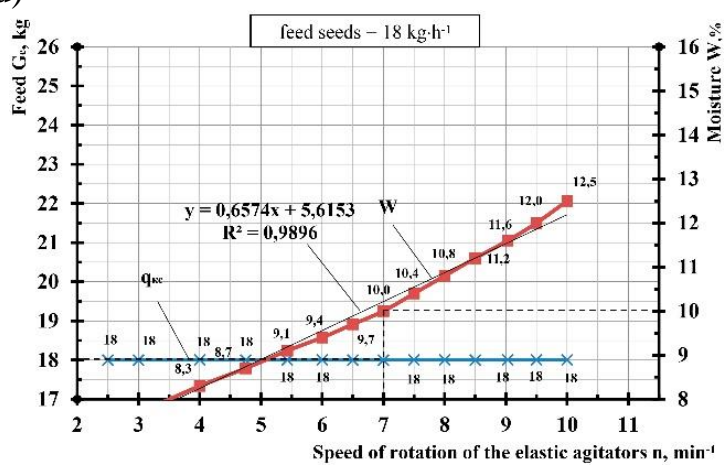

Fig. 4. Dependence of the drying chamber throughput on the rotation speed of the elastic agitators with different seeds feed into the drying chamber: $\mathrm{a}-24 \mathrm{~kg} \cdot \mathrm{h}^{-1} ; \mathrm{b}-22 \mathrm{~kg} \cdot \mathrm{h}^{-1}$;

$\mathrm{c}-20 \mathrm{~kg} \cdot \mathrm{h}^{-1} ; \mathrm{d}-18 \mathrm{~kg} \cdot \mathrm{h}^{-1} ; *-$ dependence of the drying chamber productivity on the rotation speed of the elastic agitators; - - dependence of seed moisture on the drying chamber throughput capacity

From the above, it can be concluded that the rational rotation speed of the elastic agitators at the maximum feed of seeds to the drying chamber with a $24 \mathrm{~kg} \cdot \mathrm{h}^{-1}$ is $4 \mathrm{~min}^{-1}$. At the same time, the effective transport capacity of the elastic agitators is ensured, and the required output moisture content of the seeds is achieved. As a result, a graph of the productivity of the HMMCS dryer is plotted, which connects the seed supply to the drying chamber and the rotation speed of the elastic agitators (Fig. 5).

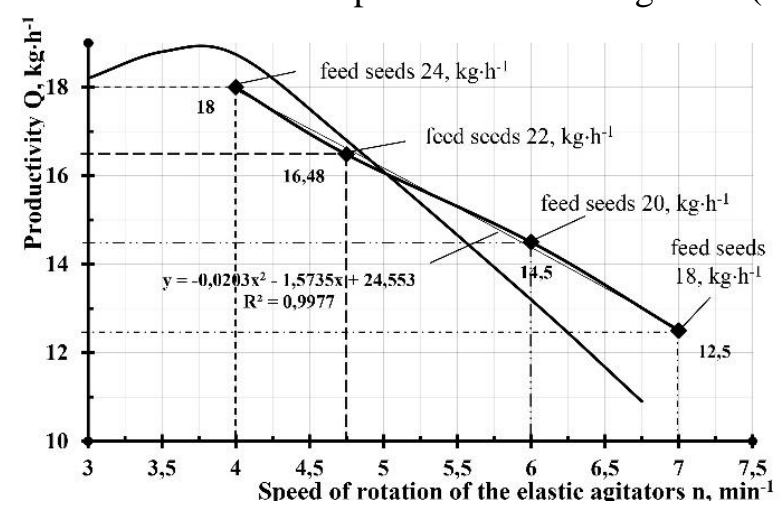

Fig. 5. Dependence of the productivity of the dryer, taking into account the supply of seeds to the drying chamber, on the speed of rotation of the elastic agitators:

-- theoretical curve; $\longrightarrow-$ experimental curve

The resulting graph allows to choose a rational speed of rotation of the elastic agitators inside the drying chamber, which will provide the required transport capacity of the elastic agitators, with different productivity of the dryer and the supply of seed material to the drying chamber. The discrepancy between the results of the previously conducted theoretical calculations [9] and the experimental studies of the productivity of the HMMCS dryer was in the range of 4-10\%. The results of the study prove the effectiveness of the use of the HMMCS dryer, in which the principle of differential heat supply to forced mixed material was implemented, which allows for a single pass of the drying chamber to obtain seed 
material of conditioned humidity from freshly deseeded melon seeds and confirm the advisability of its use for seed purposes. In the course of the experimental studies, it was revealed that an increase in the temperature of the drying agent more than $50{ }^{\circ} \mathrm{C}$ leads to the maximum permissible heating of seeds, which reduces their sowing qualities, which is also confirmed by scientific studies of other authors $[1 ; 3 ; 4]$. The results of the research are the basis for the upcoming optimization studies and provide a basis for predicting a positive economic effect in the practical application of dryers of the proposed design.

\section{Conclusions}

1. The proposed design of the dryer HMMCS, in which the principle of differential heat supply to forced mixed material was implemented, allows for a single pass of the drying chamber against the direction of movement of the drying agent to obtain seed material of conditioned moister from freshly extracted melon seeds and confirms the advisability of its use for seed purposes.

2. The following parameters and consistent patterns are established: angle of inclination of gas distribution sieve of unloading unit $14^{\circ}$; seed supply to the drying chamber $24-18 \mathrm{~kg} \cdot \mathrm{h}^{-1}$; revolutions per minute of elastic agitators when the seeds are supplied to the drying chamber $24 \mathrm{~kg} \cdot \mathrm{h}^{-1}$ $4 \mathrm{~min}^{-1}$, when the seeds are supplied $22 \mathrm{~kg} \cdot \mathrm{h}^{-1}-4.75 \mathrm{~min}^{-1}$, at $20 \mathrm{~kg} \cdot \mathrm{h}^{-1}-6 \mathrm{~min}^{-1}$ and at $18 \mathrm{~kg} \cdot \mathrm{h}^{-1}-$ $7 \mathrm{~min}^{-1}$; drying agent speed $5 \mathrm{~m} \cdot \mathrm{s}^{-1}$.

3. With the above design and technological parameters of the dryer, the specific energy consumption of the drying process of pumpkin seeds of the "Volzhskaya Seraya" variety was $1.27 \mathrm{kWh} \cdot \mathrm{kg}^{-1}$ with a dryer productivity of $18 \mathrm{~kg} \cdot \mathrm{h}^{-1}$.

4. The obtained result is the basis for the upcoming optimization studies.

\section{References}

[1] Горова Т.К., Гаврилюк М.М., Ходєєва Л.П. та ін. Насінництво й насіннєзнавство овочевих і баштанних культур. УААН, Селекційно-генетичний ін.-т. Національний центр насіннєзнавства та сортовивчення. К.: Аграрна наука, 2003, 328 с. (Gorova T., Gavriliuk M., Khodeeva L., Seed production and seed science of vegetable and melon crops., UAAN. Selektsiyno-genetichniy in.-t. Natsionalniy tsentr nasinneznavstva ta sortovivchennya. K.: Agrarna nauka, 2003, 238 p.). (In Ukraine).

[2] Solomon O., Taiwo O., Mechanization of melon processing and novel extraction technologies: A short review. Scientific African, vol. 9, 2020, pp. 20-21.

[3] Raquel P., Susana P., Maria J., Study of the convective drying of pumpkin. Food and Bioproducts Processing, vol. 89(4), 2010, pp. 422-428.

[4] Savo B., Golub M., Joachim M., Ratko O., Milan M., Convective drying of naked seeded oil pumpkin seeds (Cucurbita pepo L.) in a medium scale batch dryer with different modes of air circulation. Journal of Medicinal and Spice Plants, vol. 17(3), 2012, pp. 108-115.

[5] Iman G., Moein Z., Reza A., Ali M., Raquel P., Majid D., Investigating shrinkage and moisture diffusivity of melon seed in a microwave assisted thin layer fluidized bed dryer. Journal of Food Measurement and Characterization, vol. 11(2), 2017, 11 p.

[6] Norhashila H., Daniel I., Ezdalina R., A Preliminary Study: Kinetic Model of Drying Process of Pumpkins (Cucurbita Moschata) in a Convective Hot Air Dryer. Agriculture and Agricultural Science Procedia, vol. 2(2), 2014, pp. 345-352.

[7] Добрицкий А., Вольвак С. Сушилка семян бахчевых культур. Сельский механизатор, Вып. №12, 2019, стр. 20-21. (Dobrickiy A., Volvak S., Melons seeds dryer. Rural machine operator, vol. 12, 2019, pp. 20-21). (In Russian).

[8] Царенко О.М., Войтюк Д.Г., Швайко В.М. та ін. Механіко-технологічні властивості сільськогосподарських матеріалів. К.: Мета, 2003, 448 с. (Tsarenko O., Voitiuk D., Shvaiko V., Mechanical and technological properties of agricultural materials, K.: Meta, 2003, 448 p.). (In Ukraine).

[9] Добрицкий А. Определение производительности сушилки высоковлажных семян бахчевых культур. Инновации в АПК: проблемы и перспективы. Вып. №3 (27), 2020, стр. 43-52. (Dobrickiy A., Determination of the performance of the dryer for high-moisture seeds of melons crop. Innovations in the agro-industrial complex: problems and prospects, vol. 3(27), 2020, pp. 4352). (In Russian). 